\title{
FINANCIAL MANAGEMENT OF GENERAL PRACTITIONERS PRACTICES IN BULGARIA: FEATURES AND CHALLENGES
}

\author{
B. Parashkevova ${ }^{1}$, N. Penev ${ }^{2}$, I. Nencheva ${ }^{2}$, S. Simeonov $^{3}$, A. Zdraveska ${ }^{1}$, J. Marinova ${ }^{1}$ \\ ${ }^{1}$ Department of Social Medicine and Health Care Management, Medical Faculty, Trakia University, \\ Stara Zagora, Bulgaria \\ ${ }^{2}$ Faculty of Economics, Trakia University, Stara Zagora, Bulgaria \\ ${ }^{3}$ Regional Branch of National Health Insurance Fund, Stara Zagora, Bulgaria
}

\begin{abstract}
Primary Health Care is important for achieving social justice in ideas for people well -being and reducing inequalities in health. Primary Health Care (PHC) is being reached faster and more easily satisfies the basic health needs of people against the backdrop of limited financial resources. PHC in one country could provide care in an effective and fair way, based on general practice, with a key role for the general practitioner.General Practitioners (GPs) are owners and financial managers of their medical practices in the Primary care. Their practices are also small business enterprises providing health services for primary outpatient medical care. The purpose of this article is to analyze the principles and methodology of cash flow management in Primary care (PC). The results present the peculiarities of capital management in Primary care and challenges faced by GPs in their role as owners and managers of their small companies. The cash flows in these medical establishments have been investigated - the limitations and opportunities of GPs to do revenue management. This means they have to be able to manage their revenue within specified deadlines for incomes and to effectively manage costs and without damaging the company's image, to repay their obligations at the latest possible date.
\end{abstract}

Key words: general practitioners, primary outpatient medical care, commercial companies, cash flows.

\section{INTRODUCTION}

Every modern health system should strive to achieve tree basic goals: improving the health status of the population and reducing health inequalities; creating equal opportunities for access to health care, responsiveness to the needs and expectations of the population, quality and right of choice in the provision of health services; ensuring financial equity and protection from financial risk after medical assistance. The tendency is that there are no unlimited possibilities in this direction. Nowadays, questions relating to the amount of funding for health care are growing faster. The key to effective and efficient health care is Primary Health Care (PHC). At this level is the potentially effective use of limited financial resources to achieve a better outcome for the protection and improvement of health. The idea of health justice is strongly embedded in the concept of PHC. This concept is particularly important in efforts to tackle the deep social, economic and political causes of poor health. The relevance and impact of these factors has been confirmed over the last decade, with the establishment of the Committee of the World Health Organization for Microeconomics and Healthcare and the Committee on Social Determinants of Health $(1,2,3)$. Well-developed PHC is important for achieving social justice in ideas for people well-being and reducing inequalities in health. $\mathrm{PHC}$ is being reached faster and more easily satisfies the basic health needs of people and gives an opportunity to fill the gap between people with and without access to health care (health inequalities) against the background of limited financial resources $(2,3,4)$.

Aim: The aim of this article is to analyze the financing of GP practices after the health reform in Republic of Bulgaria.

Tasks: Presentation and discussion of: - the principles of health care financial system in the Republic of Bulgaria; - the features of the ownership of medical practices in PHC and their legal status; $\bullet$ the cash flows in the PHC; • the challenges in front of GPs as a financial managers on their medical practices. 


\section{MATERIALS AND METHODS}

Document review of scientific papers, WHO publications, and normative documents devoted to the Bulgarian Health care system was done.

\section{RESULTS AND DISCUSSION}

Nowadays in Bulgaria health care services are financed from compulsory health insurance contributions, taxes, out-of-pocket payments, voluntary health insurance premiums, corporate payments and external funding (5). After Health Reform Bulgaria has a mixed public-private health care financing system. Its transformation began in 1989 with the process of decentralization and pluralization from a tax-based system to health insurance system (6). During the second stage of the health reform (1997-2001) it was introduced: Health Insurance Act (HIA) and Medical-Treatment Facilities Act (MTFA), Law of Professional Organizations of Doctors and Dentists (LPODD). The Health Insurance Act reformed the Bulgarian health system into a health insurance system with a compulsory and voluntary component in 1998. The key players in the insurance system are the insured individuals, the health care providers and the payers - National Health Insurance Fund (NHIF), the single payer in the social health insurance (SHI) system, and voluntary health insurance companies (5). In the third stage of Health Reform (2002-present) is completed with the adoption of new laws and additions of the existing regulatory acts $(5,6)$.

The NHIF is the single institution responsible for the organization of compulsory health insurance. By the law NHIF is an autonomous public institution independent of the government. NHIF is the institution that governs financial relations with healthcare providers through a contract model. The basic package of health services and services prices are subject to negotiation between NHIF and the professional organization of physicians. Negotiation takes place annually and ends with the signing of a National Frame Contract (NFC). On the basis of the NFC, the healthcare establishments (providers of health services) conclude individual contracts with the Regional Divisions of the NHIF. By the MTFA institutions stipulates medical outpatient facilities in PHC. These are GPs outpatient medical practices whose identify as independent economic (market) subjects, according to the Commercial Act and the Cooperatives Act. According Bulgarian law GP is a central figure in PHC and acts as a gatakeeper for specialized ambulatory and hospital care $(3,4)$. GP also is an owner of a private ambulatory - medical outpatient practices. The single source of financing for these medical practices are the payments from NHIF and as an administrator of compulsory health insurance pays contracted and performed activity by GPs $(4,5,7,8)$. The NHIF finances a basic package of activities regulated by particular Ordinance of the Minister of Health, which includes: 1) Health information activities related to the patient; 2) Health Promotion - assessment of the health problems of the patient and family;

3) Prevention of diseases; 4) Follow-up clinical examinations of persons with chronic disease conditions; 5) Control of infectious diseases; 6) Diagnostic and therapeutic activity; 7) Other activities related to diagnosis and treatment; Referral for consultation; Referral and assistance for hospitalization; 8) Activities in medical expertise - Pre-employment expertise; Expertise on temporary incapacity for work and ect.; 9) The GP provides a continuous round permanent 24 hours access to consultation by telephone in clinical setting or at home of person - out-of-hours care (9). "Capitation" is a monthly payment to the provider by NHIF, based on the number of registered patients. It is differentiated according to the age of individuals recorded in the GP list. It is believed the patient has the right to choose a GP in which to register. Through the system of capitation the health provider receives regular payment whether or not the patient receives any services during this month. According to the HFC the amount received by the GPs is as follows: for 1 person under $18-1.37 \mathrm{BGN}$; for a person from 18 to $65-1,05$ BGN and for a person over $65-1,47$ BGN and payment for out-of-hours care -0.11 BGN per person (9). The second main component is payment for performed services. GPs receives a monthly payment for services including prevention and monitoring - (followup) for patients with chronic diseases $(10,11)$ : 1) Preventive activity by the Children's Health Care Program differentiated payment according to the age: $0-1$ years - $10.50 \mathrm{BGN}$; 1-2 years - $9.50 \mathrm{BGN}$; 2-7 years - $9.50 \mathrm{BGN}$; 7-18 years - 9 BGN. Immunizations are paid separately as for one activity under compulsory immunization calendar of a person from 0-18 years is $4.50 \mathrm{BGN}$; 2) Maternity health monitoring services (follow up and care of pregnant women and provision of natal assistance)- 7.00 BGN; 3) Prophylactic examinations of persons over 18 years of age $12 \mathrm{BGN}$ and for immunization of a person over 18 years - 4.50 BGN; 4) Care of chronically ill patients and persons at risk of disease - activity 
on monitoring of persons with one or more diseases - for monitoring a person with one disease - BGN 9.50, for a person with 2 diseases - BGN 11.40, for three and more BGN 13.30 (12).

The model used for financing PHC in Bulgaria is structured mixed on a capitation and a pay for performed activity. The capitation provides guaranteed funding for the GPs for the provision of medical services to those enrolled in the patient list. In recent years, the amounts of cash flows that have been received in primary care establishments have increased (6, 12). A key aspect of capitation is that payment is not linked to resources that providers use for the services or the volume of services they offer. Therefore, a fanatical risk of loss of fund is transferred from the funding agency to the contractor for medical healthcare provider. If actual costs exceed the capitation budget, the provider takes responsibility. According to economic science if he manage to achieve a certain level of efficiency, such as maintaining patients enrolled in good health, he may accumulate funds for investment (6). The question is how GPs can achieve a level of effectiveness and accumulate reinvestment funds and whether this can be done by maintaining healthy patients? With regards to the payment for the services, the GPs are compensated directly for services performed in the last month. Employing the payment for services as the only method is not validated because it does not allow the planning, regulation and control of the cash flows to the PHC from the budget of the NHIF (6).

We should also note the other two cash flows: compensation for unfavorable working conditions (from NHIF budget) and consumer tax (patient's out of pocket payment). Additional compensation GPs receive for servicing patients residing in areas designated by the NHIF as unfavorable $(6,12)$. This component recognizes and compensates for the GPs' difficulties in providing healthcare services in such areas, and thus finances small number of GP ambulatories. This is demonstrated by the ratio of the cash flows from the budget of the NHIF: $48 \%$ for capitation; $50 \%$ for services and $2 \%$ for unfavorable conditions (January - June 2017).

The consumer tax is a component complementing the funding of the GPs, believing that this type of surcharge has some dissuasive effect on the consumption of health services. Under the Health Insurance Act, patients pay a consumer tax $-1 \%$ of the minimum wage. In addition to dissuasive effect, the consumer tax is aimed at stimulating individual responsibility and an understanding of the useful value of the medical service, even though its pay is a relatively small part of the real value of the service $(6,12,13)$.

The cash flows can be summarized as revenues, mainly from the NHIF, except a consumer tax: 1) pay per capita - capitation - ; Per person per year for a package of medical activities regulated by the Ministry of Health; 2) payment for activity (mainly prophylactic, dispensary examination, immunization, etc.) and incident to a patient from another region; 3) payment for unfavorable operating conditions of the parcel, and 4) consumer tax. The costs (expenditure) incurred are (1) the salaries (nurses, midwives, general practitioners, etc.) with the largest proportion and relative share; 2) household expenses rent, electricity, heating, etc., 3) expenses for medical consumables, etc. 4) costs of social contributions, taxes, etc $(10,14)$. The incomes that form GPs are based on the difference between revenue and expenditure.

As new economic actors, GPs have to change their economic behavior in several aspects: firstly - they produce and sell their product (health service) to other economic entities; secondly - a new type of relationship is established between them and NHIF. Thirdly, their tax treatment is changed (15). GP should achieve a financial result that is formed by a positive difference between revenue and expenditure.

Bulgarian GPs are separate market subject, something completely new from $2000(16,17$, 18). In 2000 the Republic of Bulgaria introduced the institution of the general practitioner with the only possible status of the self-employed person with registration under the Commercial Act $(7,18)$. The GP's practices have a commercial registration, which identifies them as commercial companies. The MTFA (1999) regulates only private forms of medical practice in PHC, without the possibility of municipal or state participation, as opposed to medical specializated outpatinet practices in second level in health care and hospital medical practice, where public and private ownership exists (5). According to the MTFA only physician or physicians with a recognized specialty in General Medicine may organize / reveal ambulatory unit, which could be solo or group practice. The draft law, which provides an opportunity for municipal participation for registration of an ambulatory was rejected. What are the reasons for this? Most likely, for stimulation GP's personal 
initiative and their entrepreneurship. Perhaps the idea that private health care establishments and practices such as independent economic operators have greater freedom to function as self-governing in terms of their resources. In Bulgaria, the PHC is completely privatized, unlike other European countries where there is public ownership of the PHC (Sweden, Finland, Spain) $(5,10,14)$.

Challenges:The analysis shows that GPs are faced to a number of challenges, in their role as owners and financial managers of their companies $(15,16)$. On the one hand, they need to use market economy methods and seek economic efficiency - ways to revenue growth, resource management, investment to improve conditions, and ways to reduce costs, even by cutting of activities. But on the other hand, medicine and health should be medical leadership. Is it possible to invest with the only source of funding to look for efficient ways and ways of managing resources? Is it possible and appropriate to cut of activities on economic considerations?

Restrictions on financial management of cash flows may place GPs in a position not to be able to repay their debts on time. For the first time in 2017, there were cases of seizure of GPs for outstanding taxes and social security contributions. There were suffered not only the image of the GP's company (as in other market sectors), but it also suffers something more serious - meeting the collective needs for health services and access to PHC.

That what distinguishes GP's company from the other entities of the national economy is that they are representatives of the public economy that works to meet collective needs rather than profit and creates a special kind of goods (15). These are intangible goods that do not resemble traditional goods and services. The important principles of public economy are: 1) fairness - a socially acceptable and justified allocation of the costs of creating public goods between individual groups and individuals; 2) principle of impartiality decisions are made on the basis of statepolitical assessments and mechanisms and the state participates through resources and institutions in the creation of these goods (15, 17). Then we raise the question of how the state participates in the creation and distribution of health services in the PHC as a special kind of goods? Why, GPs ambulatories as a part of the public economy should act by the principles of private economy? And in the case of a failure of GP's company or lack of GPs' financial interest to register practice in an area, than who will provide access to PHC of this population? Does this mean a lack of state commitment to access to PHC and avoiding the philosophy of PHC that develops ideas for equality and universal coverage for access to PHC and resources $(8,18)$. For the first time in the nearly 140-year history of the independence of a third Bulgarian state, access to the PHC for a part of the Bulgarian population could be lost $(19,20,21)$.

\section{CONCLUSIONS}

Well-developed PHC could contribute to meet a justice demands for distribution of limited financial resources in health care, which will allow people to lead a socially and economically productive life. The last decade of the 20th century in Republic of Bulgaria sets the start of a long cycle of changes called Health Reform. The goals of the health reform put in place - improving the health of the population and building a health system that responds to people's health needs, based on democratic and market principles, have so far not been achieved. Securing primary health care, as an inviolable right for every person identified by the World Health Organization's Conference in Alma-Ata, nearly 40 years ago, is in doubt.

The philosophy of the PHC on equality and universal coverage for access to health care and resources is set to be implemented through private initiative and private entrepreneurship. GPs have the key position in PHC at the same time as the challenge as the owners of the practice and the managers of a company with a single financial source - NHIF. The GPs' practices are "autonomous market players" and should be the backbone of the Bulgarian Primary care system. GPs are faced the challenge of managing cash flow efficiently at the same time by resisting market principles and translating the philosophy of Primary Health Care.

Note: *This article is written under the Scientific Project No 11,Competition session of Medical Faculty, Trakia University, 2017 "Promotional and prevention activities for maternal and child health in primary outpatient medical care: current assessments and perspectives"

\section{REFERENCES}

1. Decision No 1350/2007 / EC of the European Parliament and of the Council of 23 October 2007 establishing a second program of Community action in the field of health (2008-2013), Official Journal of the European Union, 20.11.2007. 
2. Organisation for Economic Co-operation and Development \& European Commission (OECD \& EC) Career Guidance: A Handbook for Policy Makers, Paris: OECD, 2004, available on: http://www.oecd.org/ireland/44592

3. World Health Organization, The World Health Report 2008: Primary Health Care Now More than Ever. Geneva, Switzerland: World Health Organization, 2008, available on: http://www.who.int.

4. WONCA Europe,The European Definitions of The Key Features of the Discipline of General Practice and The Role of the General Practitioner, 2011 Edition, available on: http://www.woncaeurope.org/sites/default/f iles/documents/Definition

5. Dimova A, Rohova M, Moutafova E, Atanasova E, Koeva S, Panteli D, van Ginneken E. Bulgaria: Health system review. Health Systems in Transition, 2012, 14(3):1-186.

6. Salchev P., Primary Health Care in Bulgaria - facts and analyses, Open Society Institute, Sofia, 2011, p .80.

7. Parashkevova B., General Practitioner in the Health System - History, Development and Perspectives, Stara Zagora, 2016, p. 141. (In Bulgarian)

8. Development of Primary Health Care in the Republic of Bulgaria, European Community, PHARE Program, Ministry of Health, 1997, p.61

9. National Framework Contract 2017, Promulgated, State Gazette No. 70/19.06.1998,amended and supplemented, SG No.113/28.12.2007, available on: http://www.nhif.bg/web/guest/142

10. Kirov L., G. Ivanov, Primary outpatient medical practices In: Introduction to General Medicine and General Medical Practice, Sofia, 2012, 215-218 (In Bulgarian)

11.Opinion of the European Economic and Social Committee on 'The human resource in the health sector in Europe COM (2008) 725 available at" COM (2008) 725,

\section{PARASHKEVOVA B., et al.}

available on": http://eurlex.europa.eu/LexUriServ/.

12. Zlatanova T., R. Zlatanova-Velikova, Primary Outpatient Medical Care Problems and Perspectives, Sofia, 2008 p 211. (In Bulgarian)

13. Health Insurance Act, available on http://www.nhif.bg/web/guest/1421

14. G. Ivanov, L. Kirov. Management and Funding of Primary outpatient medical practices In: Introduction to General Medicine and General Medical Practice, Sofia, 2012, 218-226. (In Bulgarian)

15. Zlatanova T., Ts. Petrova-Gotova, N. Popov, D. Shtereva-Tsuni, R. Yaneva, Introduction to Economic Knowledge, GorexPres, Sofia, 2016, p 179(In Bulgarian)

16.Tyrnovska M., Business Ethical Dimensions Of Professional Activity In General Medical Practice, Dissertation, Plovdiv, 2014. (In Bulgarian)

17. Marinova J., K. Peeva, G. Veleva, D. Mihaylova, Management of Health Priorities in the General Practitioner's Practice - Results of Empirical Study, Social Medicine 3, 2002: 35-37. (In Bulgarian)

18. Medical-Treatment Facilities Act, available on http://www.nhif.bg/web/guest/1421

19.Parashkevova B., Y. Marinova, The Institution of the Regional Doctor in Bulgaria - Historical View, Varna Medical Forum, Volume 3, Suppl. 2, 2014: 332-342

20.B. Parashkevova, K. Marinov, J. Marinova, Regional Healthcare Services and Regional Physician - Establishment and Development in the End of the $19^{\text {th }}$ and the Beginning of $20^{\text {th }}$ Century in Bulgaria, The Trakia Journal of Sciences, The Scientific Serial of The Trakia University, 2012,Volume 10, Suppl. 3: 102-106.

21. Parashkevova B., Y. Marinova, Characteristics and Factors for Professional Career of General Practitioners - Results of Empirical Study, General Medicine, voll XVIII, 2016/2: 28-33 